\title{
Effects of free feeding time system and energy level to improve the reproductive performance of lactating sows during summer
}

\author{
Kwang Yeol Kim ${ }^{1 \#}$, Yo Han Choi ${ }^{2 \#}$, Abdolreza Hosseindoust ${ }^{1}$, Min Ju Kim", \\ Joseph Moturi ${ }^{1}$, Tae Gyun Kim ${ }^{1}$, Chang Hyun Song ${ }^{1}$, Jun Hyung Lee ${ }^{1}$ \\ and Byung Jo Chae ${ }^{1 *}$ \\ ${ }^{1}$ Department of Animal Resources Science, College of Animal Life Sciences, Kangwon National University, \\ Chuncheon 24341, Korea \\ ${ }^{2}$ Department of Animal Resources Development Swine Science Division, RDA, Cheonan 31000, Korea
}

Received: Feb 6, 2020

Revised: Mar 27, 2020

Accepted: Apr 6, 2020

\#These authors contributed equally to this work.

${ }^{*}$ Corresponding author ByungJo Chae

Department of Animal Resources Science, College of Animal Life

Sciences, Kangwon National University,

Chuncheon 24341, Korea.

Tel: +82-33-250-8616

E-mail: bjchae@kangwon.ac.kr

Copyright $\odot 2020$ Korean Society of Animal Sciences and Technology.

This is an Open Access article distributed under the terms of the Creative Commons Attribution

Non-Commercial License (http:// creativecommons.org/licenses/by$\mathrm{nc} / 4.0 /$ ) which permits unrestricted non-commercial use, distribution, and reproduction in any medium, provided the original work is properly cited.

ORCID

KwangYeol Kim

https://orcid.org/0000-0002-3723-2978 YoHan Choi

https://orcid.org/0000-0003-4710-4731 Abdolreza Hosseindoust

https://orcid.org/0000-0001-9191-0613 MinJu Kim

https://orcid.org/0000-0001-6950-0458 Joseph Moturi

https://orcid.org/0000-0002-0626-0255

TaeGyun Kim

https://orcid.org/0000-0002-9772-080X

\section{Abstract}

The reproductive performance of lactating sows was investigated by using different feeding methods including conventional feeding (CF, 3 times/d) or free feeding (FF), and different dietary energy level including low energy (LE: 3,300) or high energy (HE: $3,400 \mathrm{kcal} / \mathrm{kg}$ ) during the hot season. A total of twenty-eight crossbred (Yorkshire $\times$ Landrace) sows were distributed into four treatments as a $2 \times 2$ factorial arrangement. Sows in the FF group showed lower body weight and backfat loss $(p<0.05)$ compared with the CF group. Backfat loss during lactation was lower $(p<0.05)$ in sows fed HE diet than in that fed LE diet. There were no significant differences in litter survival rate and weaning to estrus interval, but the litter weight at weaning was improved $(p<0.05)$ in FF and HE sows. Hence, it is concluded that using the free-feeding system or increased dietary energy density leads to improved sow performance during hot ambient temperature.

Keywords: Energy, Feeding, Heat stress, Lactating sows, Piglets

\section{INTRODUCTION}

The major goal in the management of lactating sow is to enhance the capacity of voluntary feed intake to increase milk yield, preventing the excess body weight (BW) loss, and achieving a prompt weaning-to-estrus interval (WEI). Voluntary feed intake, litter growth, milk output, and WEI of sows can be compromised in the farrowing time during the heat stress period [1-3]. Wolp et al. [4] and Kim et al. [5] indicated that the adverse influences of heat stress can be related to the undeveloped physiological control of body temperature and insufficient function of sweating through the skin due to keratinized sweat glands, and thick subcutaneous fat layer.

The voluntary feed intake is the most common thermoregulatory mechanism in swine to diminish the adverse effects of high environmental temperature [6,7]. Although the reduced feed intake may minimize heat load during heat stress conditions and adversely impact the growth performance. Espe- 
Chang Hyun Song

https://orcid.org/0000-0002-0138-6924

JunHyung Lee

https://orcid.org/0000-0002-7937-7817

Byung Jo Chae

https://orcid.org/0000-0002-8570-698X

Competing interests

No potential conflict of interest relevant to

this article was reported.

Funding sources

The work was supported by the Cooperative

Research Program for Agriculture Science

and Technology Development (grant

No. 01160302), Rural Development

Administration, Korea. This study has been

worked with the support of a research grant

of Kangwon National University in 2018.

Acknowledgements

Not applicable.

Availability of data and material Upon reasonable request, the datasets of this study can be available from the corresponding author.

Authors' contributions

Conceptualization: Kim TG, Chae BJ.

Data curation: Kim TG, Lee JH.

Formal analysis: Kim MJ, Moturi J.

Methodology: Kim KY, Choi YH.

Software: Hosseindoust A, Moturi J.

Validation: Song $\mathrm{CH}$, Lee JH.

Investigation: Kim KY, Choi YH.

Writing - original draft: Kim KY.

Writing - review \& editing: Lee JH.

Ethics approval and consent to participate This experiment was aligned to the ethical standards of animal (KW-170519-1) in Institutional Animal Care and Use Committee of Kangwon National University, Chuncheon, Korea. cially, the high humidity in summer months in Korea increases the disadvantage of high temperatures. Nutritional strategies to obtain adequate feed intake can positively increase lactating sows performance. As the conventional feeders are designed to be incorporated with waterers, the ontime feed release may allow the sow to eat the meal completely and avoid unsound fermentation and decomposition of feed in the presence of water during high temperatures. Therefore, it can be assumed that this method may increase the efficiency of feeding by reducing the waste of water and feed. Although many researchers were studying feed intake under high ambient temperature, there are limited studies regarding the efficacy of automatic feeders in lactating sows. Thus, the main aim of the current study was to evaluate the influences of temperature in commercial swine farm and seasonal changes in daily feed intake of lactating sows.

\section{MATERIALS AND METHODS}

The experimental design for the current study was permitted by the Committee of Institutional Animal Care and Use at Kangwon National University, Chuncheon 24341, Korea.

\section{Animals and management}

A total of twenty-eight crossbred sows (Yorkshire $\times$ Landrace; average BW, $233.5 \pm 23.4 \mathrm{~kg}$ and 3.60 parity) were divided between four treatments after farrowing as a $2 \times 2$ factorial arrangement. The treatments were included two feeder types (CF, conventional feeding and 3 times/d; FF, free-feeding) and two levels of energy (low energy, 3,300 kcal/ $\mathrm{kg}$ and high energy, 3,400 kcal/kg). Ad libitum access to feed was provided for all lactating sows. Freshwater was available via a drinker situated in the feeder. The feeders $(0.46 \mathrm{~m} \times 0.36 \mathrm{~m} \times 0.36 \mathrm{~m})$ in CF treatment were controlled and refilled three times daily. Newly designed free-feeding feeders (KOCA, Seoul, Korea) were applied for sows in FF treatment. The FF system in this study was designed to release 200 grams of feed per meal as soon as the feeder is touched by the sow. Moreover, two minutes delay was programmed between the meals to avoid over feed release. In addition, a probe was placed in the watering pipe to restrict the release of water if the frequent touch of the waterer nipple was done by the sow due to high ambient temperature. The artificial insemination was performed 2 times at the onset of estrus, and the pregnancy confirmation test was done at $\mathrm{d}$ thirty post-breeding by an ultrasound machine (Pharvision B-mode, Ambisea Tech., Shenzhen, China). The diets were balanced based on the National Research Council (2012) standard for lactation requirements for all the treatments (Table 1). The average temperature of $28.1^{\circ} \mathrm{C} \pm 1.1^{\circ} \mathrm{C}$ was recorded in the conventional farrowing rooms.

\section{Data collection and measurement}

The evaluation of live weight was performed on d 109 of gestation (before farrowing) and d 21 of lactation (at weaning). An ultrasonic device (Agroscan A16, France) was used for the backfat thickness (BFT) measurement on $\mathrm{d} 109$ of gestation and $\mathrm{d} 21$ of lactation at the 10th rib. The BFT change during lactation was calculated by measuring the difference between BFT at $\mathrm{d} 21$ of lactation and BFT at $\mathrm{d} 109$ of gestation. Litter performance traits including the number of born and born alive piglets, BW $(\mathrm{kg})$ at farrowing and weaning, and the number of weaned piglets were recorded. In addition, the amount of feed intake and the duration of WEI were detected. The average daily gain (ADG) of weanling piglets was measured.

\section{Blood metabolites}

The blood samples (10-mL per sample) were collected on the farrowing day (day 1 of lactation) and on d 21 (weaning) of lactation by a heparin-free vacutainer tube (Becton Dickinson, Franklin, 
Table 1. Formula and chemical composition of lactation sow diets (as-fed basis)

\begin{tabular}{|c|c|c|}
\hline ME (kcal/kg) & Low energy & High energy \\
\hline Ingredients (\%) & 100.00 & 100.00 \\
\hline Corn & 62.50 & 60.56 \\
\hline SBM & 28.60 & 28.30 \\
\hline Animal fat & 2.63 & 4.75 \\
\hline Molasses & 2.00 & 2.00 \\
\hline TCP & 1.54 & 1.58 \\
\hline Limestone & 1.48 & 1.55 \\
\hline Salt & 0.50 & 0.50 \\
\hline Choline chloride (50\%) & 0.05 & 0.05 \\
\hline L-Lysine·HCl (78\%) & 0.05 & 0.05 \\
\hline DL-Methionine (99.8\%) & - & 0.02 \\
\hline L-Threonine (98.5\%) & 0.03 & 0.03 \\
\hline L-Tryptophan (10\%) & 0.18 & 0.17 \\
\hline L-Valine $(98.5 \%)$ & 0.09 & 0.09 \\
\hline Vitamin premix ${ }^{1)}$ & 0.15 & 0.15 \\
\hline Mineral premix ${ }^{2)}$ & 0.15 & 0.15 \\
\hline Phytase & 0.05 & 0.05 \\
\hline \multicolumn{3}{|c|}{ Calculated composition (g/100 g DM) } \\
\hline $\mathrm{ME}(\mathrm{kcal} / \mathrm{kg})$ & 3,300 & 3,400 \\
\hline $\mathrm{CP}$ & 17.80 & 17.80 \\
\hline $\mathrm{Ca}$ & 0.88 & 0.88 \\
\hline Av. $P$ & 0.44 & 0.44 \\
\hline SID. Arg & 1.03 & 1.03 \\
\hline SID. His & 0.41 & 0.41 \\
\hline SID. lle & 0.62 & 0.62 \\
\hline SID. Leu & 1.36 & 1.36 \\
\hline SID. Lys & 0.88 & 0.88 \\
\hline SID. Met & 0.23 & 0.23 \\
\hline SID. Met + Cys & 0.48 & 0.48 \\
\hline SID. Thr & 0.56 & 0.56 \\
\hline SID. Trp & 0.18 & 0.18 \\
\hline SID. Val & 0.75 & 0.75 \\
\hline
\end{tabular}

${ }^{1)}$ Supplied per kilogram of vitamin premix: 12,000,000 IU vitamin $A, 2,400,000$ IU vitamin $D_{3}, 132,000$ IU vitamin $E, 1,500 \mathrm{mg}$ vitamin $K_{3}, 3,000 \mathrm{mg}$ vitamin $B_{1}, 11,250$ mg vitamin $B_{2}, 3,000$ mg vitamin $B_{6}, 45$ mg vitamin $B_{12}, 36,000 \mathrm{mg}$ pantothenic acid, $30,000 \mathrm{mg}$ niacin, $600 \mathrm{mg}$ biotin, $4,000 \mathrm{mg}$ folic acid.

${ }^{2)}$ Supplied per kilogram of mineral premix: 80,000 mg Fe, $170 \mathrm{mg} \mathrm{Co,} \mathrm{8,500} \mathrm{mg} \mathrm{Cu,} \mathrm{25,000} \mathrm{mg} \mathrm{Mn,} \mathrm{95,000} \mathrm{mg} \mathrm{Zn,} 140$ mg I, $150 \mathrm{mg}$ Se.

ME, metabolizable energy; SBM; soybean meal; TCP, tricalcium phosphate; SID, standardized ileal digestibility.

NJ) from jugular vein between 08:30 and 09:30. The blood plasma was separated by centrifugation $\left(3,000 \times \mathrm{g}\right.$ for $15 \mathrm{~min}$ at $\left.4{ }^{\circ} \mathrm{C}\right)$ and stored at $-20^{\circ} \mathrm{C}$ for blood metabolites analysis including blood urea nitrogen, triglyceride, glucose, creatinine, and insulin. An automated chemistry analyzer (Fuji Dri-chem 3500i, Fujifilm) and commercial kits (Fujifilm, Saitama, Japan) were used for the analysis of blood metabolites. 


\section{Hormone profiles}

At d 1 and d 21 of lactation, $10 \mathrm{~mL}$ blood samples were collected after 09:00 meal at 60-minute intervals (from 09:00 to 13:00) for $4 \mathrm{~h}$ to analyze luteinizing hormone (LH) and follicle-stimulating hormone (FSH). Swine insulin, FSH, and LH kits (Endocrine Technologies, Newark, CA, USA) were applied and the concentrations of hormones were measured (in duplicate) with the ELISA method by Biolog Micro Station system. The intra-assay coefficient of variation (CV) for insulin, $\mathrm{LH}$, and FSH were $2.66 \%, 14.68 \%$, and $8.81 \%$, and inter-assay CV was $17.32 \%, 5.35 \%$, and $18.14 \%$, respectively.

\section{Colostrum and milk composition}

The evaluation of milk and clostridium ( $25 \mathrm{~mL}$ sample) composition including total solid, protein, fat, and lactose was performed at $\mathrm{d} 1$ and d 10 postpartum. One $\mathrm{mL}$ of oxytocin $(1 \mathrm{U} / \mathrm{mL})$ was applied intravenously to stimulate lactating sow milk release. Milk was manually collected from all functional teats. At the next step, milk and colostrum samples were frozen at $-20^{\circ} \mathrm{C}$ to analyze the parameters by Milko Scan infrared milk analyzer (Foss Electric, Hillerød, Denmark).

\section{Statistical analyses}

The GLM procedure of the SAS package (SAS. 2012; SAS Inst., Cary, NC, USA) was applied for statistical analysis as a $2 \times 2$ factorial arrangement and a complete block design. The main effects of feeding types and energy levels and their interaction terms were considered in the statistical model. The significant differences were separated by using Tukey's honestly significant difference test. In all variables analyzed, the individual sow was identified as an experimental unit. Probability values of < 0.05 were considered significant.

\section{RESULTS}

\section{Sow performance}

The body condition result, daily feed intake, and WEI of sows are presented in Table 2. There was no interaction between the energy level and feeder type for the measured variables. The BW change and daily feed intake during lactation were significantly effected $(p<0.05)$ by the FF treatment. Energy level had no effects on BW, BFT, daily feed intake and WEI of lactating sows during the summer season.

\section{Litter performance}

The influence of feeder type and energy level on litter performance is shown in Table 3. There were no significant effects of feeder type and energy level on litter size, piglets weaned, and survival rate. The litter weight at weaning, total weight gain, and average weight gain were increased in the FF and high energy diet treatments.

\section{Blood metabolites}

Blood metabolites of sows are shown in Table 4. There were no significant effects between the feeding type and energy level on blood urea nitrogen, glucose, triglyceride, and creatinine at post farrowing and weaning times during the summer season.

\section{Hormone profiles}

The effects of feeder type and energy level are shown in Table 5. There were no interaction effects between feeder type and energy level on hormone profiles $(p>0.05)$. There were no significant 
Table 2. Effects of feeding type and dietary energy level on backfat thickness change, feed intake and weaning to estrus interval in sows during summer season

\begin{tabular}{|c|c|c|c|c|c|c|c|c|}
\hline \multirow{2}{*}{ Item $^{1)}$} & \multicolumn{2}{|c|}{ Feeding type } & \multicolumn{2}{|c|}{ Energy level (ME, kcal/kg) } & \multirow{2}{*}{ SEM } & \multicolumn{3}{|c|}{$p$-value } \\
\hline & CF & FF & 3,300 & 3,400 & & $\mathbf{F}$ & $E$ & $F \times E$ \\
\hline Parity & 3.61 & 3.52 & 3.59 & 3.51 & 0.37 & 0.701 & 0.998 & 0.848 \\
\hline \multicolumn{9}{|l|}{ Sow body weight $(\mathrm{kg})$} \\
\hline Gestation (d 109) & 233.53 & 231.08 & 233.92 & 230.68 & 6.51 & 0.517 & 0.834 & 0.660 \\
\hline Weaning & 214.92 & 215.37 & 215.55 & 214.74 & 6.00 & 0.828 & 0.875 & 0.724 \\
\hline Change (-) & 18.61 & 15.71 & 18.37 & 15.94 & 1.34 & 0.031 & 0.084 & 0.579 \\
\hline \multicolumn{9}{|l|}{ Sow backfat thickness (mm) } \\
\hline Gestation (d 109) & 20.92 & 20.99 & 21.23 & 20.68 & 0.69 & 0.934 & 0.538 & 0.750 \\
\hline Weanling & 16.67 & 17.36 & 16.92 & 17.11 & 0.44 & 0.182 & 0.537 & 0.298 \\
\hline Change (-) & 4.26 & 3.62 & 4.31 & 3.57 & 0.37 & 0.089 & 0.070 & 0.517 \\
\hline Daily feed intake (kg/d) & 4.52 & 5.13 & 4.93 & 4.73 & 0.11 & 0.001 & 0.124 & 0.401 \\
\hline Weaning to estrus interval (d) & 5.25 & 4.71 & 5.14 & 4.82 & 0.38 & 0.169 & 0.407 & 0.926 \\
\hline
\end{tabular}

${ }^{1)}$ Data are means of seven replicates.

SEM, Standard error of means; $C F$, conventional feeding; FF, free feeding; $F$, feeding type, $E$, dietary energy level, $F \times E$, feeding type $\times$ dietary energy level.

Table 3. Effects of feeding type and dietary energy level on litter size and piglet performance in sows during summer season

\begin{tabular}{|c|c|c|c|c|c|c|c|c|}
\hline \multirow{2}{*}{ Item $^{1)}$} & \multicolumn{2}{|c|}{ Feeding type } & \multicolumn{2}{|c|}{ Energy level (ME, kcal/kg) } & \multirow{2}{*}{ SEM } & \multicolumn{3}{|c|}{$p$-value } \\
\hline & CF & FF & 3,300 & 3,400 & & $\mathbf{F}$ & $\mathbf{E}$ & $F \times E$ \\
\hline \multicolumn{9}{|l|}{ Litter size } \\
\hline Initial litter size & 11.68 & 11.74 & 11.67 & 11.75 & 0.23 & 0.997 & 0.541 & 0.361 \\
\hline Piglets weaned & 11.25 & 11.40 & 11.22 & 11.43 & 0.25 & 0.673 & 0.326 & 0.482 \\
\hline Survival rate (\%) & 96.38 & 97.11 & 96.13 & 97.36 & 1.13 & 0.459 & 0.331 & 0.825 \\
\hline \multicolumn{9}{|l|}{ Litter weight (kg) } \\
\hline Initial (d 1) & 15.95 & 16.28 & 16.10 & 16.14 & 0.36 & 0.646 & 0.587 & 0.548 \\
\hline Initial (kg/pig, d 1) & 1.37 & 1.39 & 1.38 & 1.38 & 0.01 & 0.312 & 0.944 & 0.759 \\
\hline Weaning (d 21) & 69.01 & 73.92 & 69.88 & 73.05 & 1.61 & 0.006 & 0.033 & 0.833 \\
\hline Weaning (kg/pig, d 21) & 6.14 & 6.49 & 6.23 & 6.40 & 0.06 & 0.001 & 0.007 & 0.195 \\
\hline Total weight gain & 53.06 & 57.65 & 53.79 & 56.92 & 1.35 & 0.002 & 0.017 & 0.932 \\
\hline Average weight gain (g/pig) & 224.27 & 240.88 & 228.18 & 237.17 & 3.08 & 0.001 & 0.002 & 0.466 \\
\hline
\end{tabular}

${ }^{1)}$ Data are means of seven replicates.

SEM, standard error of means; CF, conventional feeding; FF, free feeding; F, feeding type, E, dietary energy level, $F \times E$, feeding type $\times$ dietary energy level.

Table 4. Effects of feeding type and dietary energy level on blood metabolites of lactating sows during summer season

\begin{tabular}{|c|c|c|c|c|c|c|c|c|}
\hline \multirow{2}{*}{ Item $^{1)}$} & \multicolumn{2}{|c|}{ Feeding type } & \multicolumn{2}{|c|}{ Energy level (ME, kcal/kg) } & \multirow{2}{*}{ SEM } & \multicolumn{3}{|c|}{$p$-value } \\
\hline & CF & FF & 3,300 & 3,400 & & $\mathbf{F}$ & E & $F \times E$ \\
\hline \multicolumn{9}{|l|}{ Post farrowing (mg/dL) } \\
\hline Glucose & 93.57 & 90.12 & 91.96 & 91.72 & 4.12 & 0.408 & 0.954 & 0.602 \\
\hline Triglyceride & 42.21 & 42.58 & 42.09 & 42.70 & 2.88 & 0.898 & 0.832 & 0.562 \\
\hline Blood urea nitrogen & 20.98 & 20.49 & 20.96 & 20.51 & 0.95 & 0.610 & 0.643 & 0.446 \\
\hline Glucose & 92.57 & 97.13 & 94.03 & 95.67 & 5.78 & 0.443 & 0.782 & 0.941 \\
\hline Triglyceride & 24.67 & 26.84 & 25.18 & 26.33 & 1.41 & 0.130 & 0.419 & 0.891 \\
\hline Creatinine & 1.69 & 1.62 & 1.65 & 1.66 & 0.10 & 0.458 & 0.882 & 0.703 \\
\hline
\end{tabular}

1)Data are means of seven replicates.

SEM, standard error of means; $C F$, conventional feeding; $F F$, free feeding; $F$, feeding type, $E$, dietary energy level, $F \times E$, feeding type $\times$ dietary energy level. 
effects on the FSH, LH, cortisol, and insulin of post farrowing and weanling sows during the summer season $(p>0.05)$.

\section{Milk and colostrum composition}

Colostrum and milk composition are shown in Table 6. There were no feeder type and energy level interactions for any of the measured variables. The colostrum and milk composition of lactating sows were unaffected by the feeder type and energy level during the summer season.

\section{DISCUSSION}

In this study, the BW change and daily feed intake change were reduced in the FF sows. Moreover, there was a tendency towards significantly reduced BFT in the FF sows. It is commonly recognized that the BFT and negative energy balance affect the reproductive performance of sows in subsequent parities [8,9]. Furthermore, the higher fluctuations in the pattern of feed intake and milk yield decrease the BFT uniformity and increase the BFT loss at weaning $[9,10]$. The variation in

Table 5. Effects of feeding type and dietary energy level on hormone profiles of lactating sows during summer season

\begin{tabular}{|c|c|c|c|c|c|c|c|c|}
\hline \multirow{2}{*}{ Item $^{1)}$} & \multicolumn{2}{|c|}{ Feeding type } & \multicolumn{2}{|c|}{ Energy level (ME, kcal/kg) } & \multirow{2}{*}{ SEM } & \multicolumn{3}{|c|}{$p$-value } \\
\hline & CF & FF & 3,300 & 3,400 & & $\mathbf{F}$ & $E$ & $F \times E$ \\
\hline \multicolumn{9}{|l|}{ Post farrowing } \\
\hline $\mathrm{LH}(\mathrm{ng} / \mathrm{mL})$ & 0.35 & 0.34 & 0.35 & 0.33 & 0.03 & 0.818 & 0.541 & 0.756 \\
\hline Insulin (uU/mL) & 2.36 & 2.39 & 2.40 & 2.35 & 0.28 & 0.926 & 0.867 & 0.629 \\
\hline $\mathrm{FSH}(\mathrm{ng} / \mathrm{mL})$ & 2.73 & 2.80 & 2.74 & 2.79 & 0.12 & 0.597 & 0.733 & 0.984 \\
\hline $\mathrm{LH}(\mathrm{ng} / \mathrm{mL})$ & 0.63 & 0.67 & 0.64 & 0.66 & 0.05 & 0.438 & 0.633 & 0.911 \\
\hline Insulin (uU/mL) & 1.40 & 1.58 & 1.45 & 1.53 & 0.10 & 0.074 & 0.506 & 0.870 \\
\hline Cortisol (ug/mL) & 5.02 & 4.32 & 4.89 & 4.44 & 0.46 & 0.132 & 0.327 & 0.601 \\
\hline
\end{tabular}

1)Data are means of seven replicates.

SEM, standard error of means; $C F$, conventional feeding; FF, free feeding; $F$, feeding type, $E$, dietary energy level, $F \times E$, feeding type $\times$ dietary energy level.

Table 6. Effects of feeding type and dietary energy level on colostrum and milk composition of lactating sows during summer season

\begin{tabular}{|c|c|c|c|c|c|c|c|c|}
\hline \multirow{2}{*}{ Item $^{1)}$} & \multicolumn{2}{|c|}{ Feeding type } & \multicolumn{2}{|c|}{ Energy level (ME, kcal/kg) } & \multirow{2}{*}{ SEM } & \multicolumn{3}{|c|}{$p$-value } \\
\hline & CF & FF & 3,300 & 3,400 & & $\mathbf{F}$ & $\mathbf{E}$ & $F \times E$ \\
\hline \multicolumn{9}{|l|}{ Colostrum (\%) } \\
\hline Protein & 15.65 & 15.32 & 14.70 & 15.19 & 0.44 & 0.220 & 0.853 & 0.349 \\
\hline Fat & 5.44 & 5.14 & 5.05 & 5.31 & 0.33 & 0.756 & 0.947 & 0.399 \\
\hline Total solid & 17.53 & 18.26 & 18.47 & 18.83 & 0.98 & 0.444 & 0.582 & 0.849 \\
\hline Protein & 5.46 & 5.65 & 5.89 & 6.08 & 0.30 & 0.162 & 0.525 & 0.993 \\
\hline Fat & 7.08 & 7.28 & 7.36 & 7.61 & 0.34 & 0.373 & 0.510 & 0.937 \\
\hline Lactose & 5.07 & 5.24 & 5.38 & 5.55 & 0.42 & 0.464 & 0.699 & 0.993 \\
\hline
\end{tabular}

${ }^{1)}$ Data are means of seven replicates.

SEM, standard error of means; $C F$, conventional feeding; FF, free feeding; $F$, feeding type, $E$, dietary energy level, $F \times E$, feeding type $\times$ dietary energy level. 
sow's BFT and BW during lactation are associated with feed intake, however, they may be related to the stress patterns as well as the result of this study also showed a decreased piglet ADG in the $\mathrm{CF}$ lactating sows during summer. Acute heat stress has severe adverse effects on BW, which are related to the limited voluntary feed intake [11]. In addition, energy expenditure is much higher during heat stress due to body thermoregulation $[12,13]$. There is a positive relationship between the feed intake pattern and energy requirement during lactation because a big share of the required energy is allocated to milk production [9]. Thus, improving the feed intake pattern is crucial to increase voluntary feed intake. Supplemental fat in lactation diets has been reported to be beneficial [14-16], particularly when sows are exposed to high ambient temperature [12,17,18]. However, this study showed no relationship between the energy level and BW, BFT, daily feed intake, and WEI.

In the present study, the addition of 3,400 kcal/kg metabolizable energy (ME) increased piglet performances. Increasing the energy levels with additional fats or oils in diets is known as a nutritional strategy to support lactating sow exposed to heat stress [19,20], particularly in prolific lactating sows [9]. The increase in supplementation of fat and oil in lactation diets from $2 \%$ to $11 \%$ enhanced the energy intake of around 1,100 kcal ME per day [21]. As energy is a high nutritional priority in lactating sows, a large share of additional energy dedicates to milk production to increase the milk fat yield [21]. Therefore, the advantages of high energy consumption may explain the improvements in litter performance due to high milk yield [20,21]. Moreover, the higher voluntary feed intake has a positive relationship with the body energy reserve and milk output in lactating sows [9]. As expected, sows in the FF treatment showed a lower body weight loss but an improved litter performance.

The blood metabolites and hormone profiles were not affected by feeding type and energy level. It has been reported that reduced feed intake decreases plasma glucose levels [22]. However, the increased feed intake in the FF treatment did not result in higher blood glucose. In agreement, Farmer et al. [23] reported no change in the level of glucose in lactating sows subjected to high ambient temperature. Regarding the differences between the current study and previously reported results, a better knowledge of the influence of blood parameters during high temperature is required.

Several studies reported that higher feed intake increases the milk yield of lactating sows, which directly affects the litter growth performance [9,24]. The insignificant differences in the milk and colostrum composition in this study may suggest that the milk yield of sows in the FF and high energy diet might be improved because of the higher litter growth performance. The larger litter size in the modern farms requires substantially higher energy in lactating sows, because between $65 \%$ to $85 \%$ of energy requirements dedicates to milk production [25]. Therefore, the concentration of dietary energy by supplementing fat or oil is a determinant factor to maintain the requirement of lactating sows.

In conclusion, the free feeding time system showed a significantly greater influence on litter performance and feed intake of lactating sows during summer and can be recommended as a practical feeding system in commercial farms. Moreover, the energy level of the diet can be increased to 3,400 kcal during summer due to the increased litter performance.

\section{REFERENCES}

1. Baumgard LH, Rhoads RP. Effects of heat stress on postabsorptive metabolism and energetics. Annu Rev Anim Biosci. 2013;1:311-37.

2. Ross JW, Hale BJ, Gabler NK, Rhoads RP, Keating AF, Baumgard LH. Physiological consequences of heat stress in pigs. Anim Prod Sci. 2015;55:1381-90.

3. Kim KY, Choi YH, Hosseindoust A, Kim MJ, Hwang SJ, Bu MS, et al. Evaluation of high 
nutrient diets and additional dextrose on reproductive performance and litter performance of heat-stressed lactating sows.J Anim Sci. 2019;90:1212-9.

4. Wolp RC, Rodrigues NEB, Zangeronimo MG, Cantarelli VS, Fialho ET, Philomeno R, et al. Soybean oil and crude protein levels for growing pigs kept under heat stress conditions. Livest Sci. 2012;147:148-53.

5. Kim DW, Kim YH, Kim KS, Kim KH. Effect of mixing of suckling piglets on change of body surface temperature in sows and piglets. J Korea Acad-Ind Coop Soc. 2017;18:135-40.

6. Quiniou N, Noblet J. Influence of high ambient temperatures on performance of multiparous lactating sows. J Anim Sci. 1999;77:2124-34.

7. Choi YH, Hosseindoust A, Kim JS, Lee SH, Kim MJ, Kumar A, et al. An overview of hourly rhythm of demand-feeding pattern by a controlled feeding system on productive performance of lactating sows during summer. Ital J Anim Sci. 2018;17:1001-9.

8. Houde AA, Methot S, Murphy BD, Bordignon V, Palin MF. Relationships between backfat thickness and reproductive efficiency of sows: a two-year trial involving two commercial herds fixing backfat thickness at breeding. Can J Anim Sci. 2010;90:429-36.

9. Strathe AV, Bruun TS, Hansen CF. Sows with high milk production had both a high feed intake and high body mobilization. Animal. 2017;11:1913-21.

10. Maes DGD, Janssens GPJ, Delputte P, Lammertyn A, de Kruif A. Back fat measurements in sows from three commercial pig herds: relationship with reproductive efficiency and correlation with visual body condition scores. Livest Prod Sci. 2004;91:57-67.

11. Silva BAN, Oliveira RFM, Donzele JL, Fernandes HC, Lima AL, Renaudeau D, et al. Effect of floor cooling and dietary amino acids content on performance and behaviour of lactating primiparous sows during summer. Livest Sci. 2009;120:25-34.

12. Neil M. Ad libitum lactation feeding of sows introduced immediately before, at, or after farrowing. Anim Sci. 1996;63:497-505.

13. Mordenti A, Bosi P, Corino C, Crovetto GM, Casa GD, Franci O, et al. Nutrient requirements of heavy pig. Ital J Anim Sci. 2003;2:73-87.

14. Stahly TS, Cromwell GL, Simpson WS. Effects of level and source of supplemental fat in the lactation diet of sows on the performance of pigs from birth to market weight. J Anim Sci. 1980;51:352-60.

15. Shurson GC, Irvin KM. Effects of genetic line and supplemental dietary fat on lactation performance of Duroc and Landrace sows.J Anim Sci. 1992;70:2942-9.

16. Averette LA, Odle J, Monaco MH, Donovan SM. Dietary fat during pregnancy and lactation increases milk fat and insulin-like growth factor I concentrations and improves neonatal growth rates in swine. J Nutr. 1999;129:2123-9.

17. Coffey MT, Seerley RW, Martin RJ, Mabry JW. Effect of level, source and duration of feeding of supplemental energy in sow diets on metabolic and hormonal traits related to energy utilization in the baby pig.J Anim Sci. 1982;55:329-36.

18. Spencer JD, Boyd RD, Cabrera R, Allee GL. Early weaning to reduce tissue mobilization in lactating sows and milk supplementation to enhance pig weaning weight during extreme heat stress. J Anim Sci. 2003;81:2041-52.

19. Xue L, Piao X, Li D, Li P, Zhang R, Kim SW, et al. The effect of the ratio of standardized ileal digestible lysine to metabolizable energy on growth performance, blood metabolites and hormones of lactating sows. J Anim Sci Biotechnol. 2012;3:11.

20. Rosero DS, Van Heugten E, Odle J, Arellano C, Boyd RD. Response of the modern lactating sow and progeny to source and level of supplemental dietary fat during high ambient temperatures.J Anim Sci. 2012;90:2609-19. 
21. Rosero DS, Odle J, Mendoza SM, Boyd RD, Fellner V, Van Heugten E. Impact of dietary lipids on sow milk composition and balance of essential fatty acids during lactation in prolific sows. J Anim Sci. 2015;93:2935-47.

22. Pearce SC, Gabler NK, Ross JW, Escobar J, Patience JF, Rhoads RP, et al. The effects of heat stress and plane of nutrition on metabolism in growing pigs.J Anim Sci. 2013;91:2108-18.

23. Farmer C, Knight C, Flint D. Mammary gland involution and endocrine status in sows: effects of weaning age and lactation heat stress. Can J Anim Sci. 2007;87:35-43.

24. Kim KH, Hosseindoust A, Ingale SL, Lee SH, Noh HS, Choi YH, et al. Effects of gestational housing on reproductive performance and behavior of sows with different backfat thickness. Asian-Australas J Anim Sci. 2016;29:142-8.

25. NRC [National Research Council]. Nutrient requirements of swine. 11th ed. Washington, DC: National Academies Press; 2012.p. 420. 